\title{
Perspectives in Sociology of Education: Basil Bernstein and Popular Education
}

\author{
Ivonaldo Leite \\ Center for Applied Science and Education Federal \\ University of Paraíba, Brazil \\ Email: ivonaldo.leite [AT] gmail.com
}

\begin{abstract}
This paper aims to describe some contributions of the British sociologist Basil Bernstein to Popular Education. In this sense, methodologically, it reviews Bernstein's main works and addresses some bases and perspectives of Popular Education. Thus, initially the paper develops an approach on Bernstein's thought and then focuses on Popular Education, taking into account its European and Latin American characterisation. It finds out three contributions in Bernstein's sociology that are important for Popular Education, namely, (1) the theorization about speech codes; (2) the approach on so-called communicative pedagogy; (3) the dimension related to social change.
\end{abstract}

Keywords---- Bernstein, Popular Education, sociology, Latin America, Europe, school, students

\section{INTRODUCTION}

Basil Bernstein was one of the leading sociologists in the world, whose pioneering work illuminated our understanding of the relationship among political economy, family, language and schooling. He was born on 1 November 1924 and died on 24 September 2000.

Son of a Jewish immigrant family and raised in London's East End, Bernstein's career reflected his concern for understanding and eliminating the barriers to upward social mobility, according to Sadovnik (2001). He served as an underage bombardier in Africa in the Second World War and worked in the Stepney settlement boys club for underprivileged Jewish children. He put himself through the London School of Economics by working various menial jobs and earned a degree in sociology. In 1960, Bernstein began graduate work at University College, London, where he completed his Ph.D. in linguistics. He then moved to the Institute of Education, where he stayed for his entire career.

Bernstein developed a wide and diverse sociological approach. From his early works on language, communication codes and schooling, to his later works on pedagogic discourse, practice and educational transmissions, he produced a theory of social and educational codes and their effect on social reproduction. Bernstein's sociology drew on the essential theoretical orientations in the field - Durkheimian, Weberian, Marxist, and interactionist - and provided the possibility of an important synthesis (Sadovnik, 2001). Sometimes, his work was misunderstood and incorrectly labelled a form of 'cultural deficit' theory. I think that's a big mistake. Bernstein (1961a) emphasized the defence of social justice and stated that he was committed to preventing the wastage of working class educational potential.

\section{BERNSTEIN'S APPROACHES}

Bernstein's early work discussed social class differences in language and raised important questions about the relationships among the social division of labour, the family and the school, and explored how these relationships affected differences in learning among the social classes. On the other hand, his later work (Bernstein, 1977) began the hard project of connecting power and class relations to the educational processes of the school. In this way, Bernstein's work connected the societal, institutional, interactional and intrapsychic levels of sociological analysis. Some reproduction theorists, like Bowles and Gintis (1976), have also developed an approach similar to that perspective, but it's an overtly deterministic view of schools without describing or explaining what goes on in them.

In his early work on language, Bernstein analysed the relationship among public language, authority and shared meanings, as well as began the development of code theory through the introduction of the concepts of restricted and elaborated codes (Bernstein, 1958; 1960; 1961b; 1962a; 1962b). Bernstein's sociolinguistic code theory was developed into a social theory examining the relationships among social class, family and the reproduction of meaning systems. In this way, code refers to the principles regulating meaning systems.

For him, there were social class differences in the communication codes of working class and middle class children, and these differences reflect the class and power relations in the social division of labour, family and schools. Then, he distinguished between the restricted code of the working class and the elaborated code of the middle class. Restricted codes are context dependent and particularistic, whereas elaborated codes are context independent and universalistic. Bernstein's critics stated that his sociolinguistic theory represented an example of deficit theory, alleging that he was arguing that working class language was deficient (Danzig, 1995). But he rejected this interpretation. 
Consistently, Bernstein affirmed that restricted codes are not deficient, but rather are functionally related to the social division of labour, where context dependent language is necessary in the context of production. Likewise, the elaborated code of the middle classes represents functional changes necessitated by changes in the division of labour and the middle classes' new position in reproduction, rather than production. According to him, that schools require an elaborated code for success means that working class children are disadvantaged by the dominant code of schooling, not that their language is deficient; for him, difference became deficit in the context of macro-power relations.

The concept of code was central to Bernstein's sociology of education. From the outset of its use in his work on language (restricted and elaborated codes), code refers to a regulative principle which underlies various message systems, especially curriculum and pedagogy (Atkinson, 1985). Curriculum and pedagogy are considered message systems, and with a third system, evaluation, they constitute the structure and processes of school knowledge, transmission and practice. According to Bernstein's own words, "curriculum defines what counts as valid knowledge, pedagogy defines what counts as valid transmission of knowledge, and evaluation defines what counts as a valid realization of the knowledge on the part of the taught" (Bersntein, 1973, p. 85). So, we can understand his theory of education in terms of the concepts of classification, framing and evaluation, and their relationship to the structural aspects of his sociological project (Sadovnik, 2001). Moreover, Bernstein's analysis of the social-class assumptions of pedagogic discourse and practice is the foundation for linking microeducational processes to the macrosociological levels of social structure and class and power relations.

It is also important to understand, according to Bernstein's sociology, that all knowledge is recontextualized from its field of production to be transmitted and acquired in educational settings. Recontextualising rules operate through 'pedagogic discourse' made up of 'instructional discourse' and 'regulative discourse' to distinguish between, on the one hand, discourse for transmitting specific knowledge and skills, and, on the other, discourse for transmitting dispositions for learning. Regulative discourse dominates instructional discourse in creating pedagogised subjects. Thus, the form of social science taught in university departments is not reflective of the discipline as a whole, rather it is ordered by pedagogic discourse which legitimates particular theories or methods at any given time and place, thereby excluding much of what is being produced broadly in the fields of social science.

He identifies two contexts for recontextualising, and universities, uniquely, encompass both (Bernstein, 1990). Primary contexts are where texts are developed. In social science this is the context of researcher and tends to be funded by the state via research councils: this context itself is changing as state-funded research is increasingly tied to outcomes that tangibly benefit society either economically or socially. Secondary contexts are those in which recontextualising agents responsible for pedagogising subjects (for instance, university teachers, quality managers, educational developers and so on) draw upon, order and sequence material in the field of reproduction (the university department).

The processes of selection are influenced by what Bernstein terms the 'pedagogic recontextualising field', that is, the teachers themselves and those who produce knowledges about pedagogic practices (for example, education departments and staff development units); and by the 'official pedagogic recontextualising field', the 'specialised departments and sub-agents of the state' (for instance, the department of Business, Innovation and Skills, funding councils and QAA). Recontextualising agents appropriate and reposition primary texts through the design of curricula; the production of documents (curriculum, quality, strategies at departmental, university and national levels); the organisation of modes of teaching; the conduct of lectures and seminar; assessment regimes and so on (McLean, Abbas, Ashwin, 2012).

Bernstein also focuses on the theme of democracy and pedagogical rights. He establishes two conditions for democracy: (1) that people feel they have a 'stake' in society, that is, they feel they have both rights to receive and obligations to give (2) that people have confidence in the political arrangements created to realise the stake. In his perspective, for the two conditions to be realized, three interrelated rights should be institutionalized. Each right creates conditions for what, in Amartya Sen's terms (McLean, Abbas, Ashwin, 2012), might be called a 'capability' and each operates at a different level, as follows: 
Table 1: Pedagogics Rights

\begin{tabular}{|l|l|l|l|}
\hline \multicolumn{1}{|c|}{ Right } & \multicolumn{1}{|c|}{ Level } & \multicolumn{1}{c|}{ Definition } & \multicolumn{1}{c|}{ Capability } \\
\hline Enhancement & Individual & $\begin{array}{l}\text { A condition for experiencing boundaries as tension } \\
\text { points condensing the past and opening possible } \\
\text { futures the right to the means of critical } \\
\text { understanding and to new possibilities. }\end{array}$ & Confidence \\
\hline Inclusion & Social & $\begin{array}{l}\text { The right to be included socially, intellectually, } \\
\text { culturally and personally including the right to be } \\
\text { autonomous.' }\end{array}$ & $\begin{array}{l}\text { Communitas' } \\
\text { Belonging in groups }\end{array}$ \\
\hline Participation & Political & $\begin{array}{l}\text { The right to participate in discourse and practices } \\
\text { that have outcomes: 'to participate in the } \\
\text { construction, maintenance and transformation of } \\
\text { social order' }\end{array}$ & $\begin{array}{l}\text { Civic discussion } \\
\text { and action }\end{array}$ \\
\hline
\end{tabular}

Source: Adapted from Bernstein (2000).

Basically, pedagogic rights are about the extent to which education (formal and informal) frees people to imagine and act or, on the contrary, the extent to which it bounds imagination and what it seems possible to do and be.

Bernstein had a profound influence on sociological research on education, and some of his approaches are related to the field of so-called Popular Education. However, his contributions have not being noticed in such a field. This fact is incomprehensible, mainly because the analytical connection between Popular Education and other contemporary theorists has often been made, like, for example, with Jürgen Habermas, according to the focus developed by Morrow and Torres (2002).

Therefore, in the following, I will highlight some bases of Popular Education to demonstrate its analytical connection points with Bernstein's thought.

\section{POPULAR EDUCATION: SOME BASES AND PERSPECTIVES}

As Kane (2013) affirms, the meaning of Popular Education has varied according to where, when and by whom it has been cited. In this way, Braster (2011) and Tiana Ferrer (2011) analyse the term historically and Steele (2007) charts a variety of interpretations and practices in Europe, from middle ages onward. In the 1960s and 1970s, having been inspired by the ideas of the Brazilian educationist Paulo Freire $(1970,1993)$ when Latin America made imaginative developments in theory and practice (Kane, 2001; Carrillo, 2011) they strongly influenced the global approaches to Popular Education, albeit in some contexts terms like 'radical education' or 'education for transformation' retained more currency.

Specifically, in Spanish and Portuguese, the lingua francas of Latin America, the adjective 'popular' suggests belonging to the people, the majority of a nation's who, in the Latin American context, are usually poor. So,

It carries connotations of social class and could often be translated into English simply as 'poor' or 'working class'. 'Educación popular (Spanish) or 'educação popular' (Portuguese), then, communicates the idea of an education of and for 'the people' rather than elite. More recently, as people organised around issue like gender, human rights and interculturalism, 'popular' stretched to include these initiatives too; since the mass of people involved come from lower economic sectors anyway, however, class-based nuances generally still apply (Kane, 2013, p. 82).

It can certainly be said that, in Latin America, Popular Education is conceptualised as both a social movement of educators and educational philosophy-cum-practice. In other words, "on the one hand it is a broad and open movement, which a degree of articulation and organisation (such as CEAAL [the Latin American Council for Adult Education]... and other regional networks), while, on the other, it is a particular brand of critical thinking" (Zarco, 2001, p. 30). In and outside Latin America, most definitions of Popular Education now shared a number of characteristics, as they are described in the following table: 
Table 2 - Definitions of Popular Education in and outside Latin America

\begin{tabular}{|c|c|}
\hline Definitions & Guiding principle \\
\hline $\begin{array}{l}\text { All education is considered political in that if it fails to challenge social injustice } \\
\text { and inequality, by default it promotes it }\end{array}$ & Socio-political \\
\hline $\begin{array}{l}\text { Education should encourage people to be authentic 'subjects' of change, to think } \\
\text { critically and act for themselves, not follow leaders. }\end{array}$ & Socio-political and cognitive \\
\hline $\begin{array}{l}\text { There are different types of knowledge, engendered by different social } \\
\text { circumstances, and education should consist of dialogue among them. }\end{array}$ & Cognitive \\
\hline $\begin{array}{l}\text { Exciting methodologies have been developed to put proposals into practice. } \\
\text { However, while Paulo Freire critised the 'banking' ('knowledge transfer') } \\
\text { approach to education as elitist and dehumanising, the alternative is not simply } \\
\text { a formulaic application of learner-centred methods: these also can have } \\
\text { reactionary purposes. }\end{array}$ & Cognitive \\
\hline $\begin{array}{l}\text { The concern is to help groups, or movements, collectively to take action to try } \\
\text { and bring about social change. }\end{array}$ & Socio-political \\
\hline $\begin{array}{l}\text { Popular Education refers to a generic practice covering a variety of social actors } \\
\text { - from peasants to factory workers, women to Indigenous people's groups and } \\
\text { so on - and a variety of topics, whichever generate interest in bringing about } \\
\text { change. }\end{array}$ & Socio-political \\
\hline
\end{tabular}

Source: Adapted from Kane (2013)

The definitions are oriented by cognitive and socio-political principles in and outside America Latina. However, contemporary definitions of Popular Education continue to vary and none definition is definitive or absolute. Furthermore, in both Latin America and Europe there still remains variety in how Education Popular is understood, conceptually, and how it is put in practice. For example, from the point of view of the socio-political principle, it can mean Marxist, social democrat, nationalist, feminist, religious, environmentalist views, with many combinations and variations in-between (Kane, 2001; Scandrett, 2001; Nicholas, 2001).

A systematic comparison between popular education in Latin America and Europe ${ }^{1}$ reveals some differences involving the approaches in the two regions. A first difference from the European perspective in relation to America Larina is that in much of Europe state education is so widespread that by definition education means 'state education'. On the other hand, "in Latin America, state provision is variable and, where deficient, popular education can fill the vacuum. In Europe, popular education either complements or competes with state education, on the outside in social movements or on the inside, in a struggle to promote its alternative philosophy and practice" (Kane, 2013, p. 89). A second difference lies in the nature of social movements. In the Europe of wealthy economies and welfare states, theorists usually characterised social movements as more middle-class than their Latin American counterparts, concerned with deepening democracy and improving the quality of life in a post-materialist society, rather than struggling for basic material needs (ibid). Another difference is the extent to which an articulated popular education movement exists independently of the state. In Latin America it is a broad and open movement, with a degree of organisation and articulation. While the situation varies across countries, outside the state, "at least, such organisation seems significantly weaker in Europe" (ibid., p. 90).

\section{BERNSTEIN AND POPULAR EDUCATION: ANALYTICAL INSPIRATIONS}

It's possible to find out approaches in Bernstein's vast work that can inspire analyses in Popular Education. In this paper, I will focus on three of them.

The first approach refers to Bernstein's theorization taking into account the speech codes. First of all, he differentiates between language and speech codes. Language is a set of rules to which all speech codes must comply, but which speech codes are realised is a function of the culture acting through social relationships in specific contexts. So,

\footnotetext{
${ }^{1}$ That means the group of countries in the region with characteristics of relatively prosperous Western democracies. The countries of the former Soviet bloc are not included.
} 
socialisation orientates children towards specific speech codes. Consequently, the class structure influences work and educational roles and brings families into a special relationship with each other and deeply penetrates the structure of life experiences within the family. The class system has deeply marked the distribution of knowledge within society. Most have not been socialised into knowledge at the level of the meta-language of control and innovation. In fact, most people have been socialised into knowledge at the level of context-tied operation.

Therefore, there is a distinction between universalistic and particularistic orders of meaning. Universalistic meanings require principles to be made linguistically explicit. Particularistic orders of meaning are meanings in which principles are linguistically implicit. In terms of schooling, knowledge has universalistic meaning. As the term implies universalistic meaning is less tied to a given context whereas with particularistic meaning much of the meaning is embedded in the context. The central point of Bernstein's thesis is that forms of socialisation orient children towards speech codes which control access to meanings that are relatively context-tied or context-independent. Working class children are oriented towards speech codes which are relatively context-tied.

Restricted codes are more tied to a local social structure and have a reduced potential for change in principles. Where codes are elaborated, the socialised has more access to the grounds of his own socialisation, and so can enter into a reflexive relationship to the social order he has taken over. Where codes are restricted the socialised has less access to the grounds of his socialisation and this reflexiveness may be limited in range.

The speech of working-class children represents a restricted code. The restricted codes are functionally related to the social division of labour, where context dependent language is necessary in the context of production. This analytical finding has a fundamental value for Popular Education. On the one hand, such an approach reveals that it is relevant for Popular Education to focus on the factors arising from the social division of labour that influence the production and circulation of speeches in society; on the other hand, it is possible to infer from it that the work of popular educators must take into account the transition from restricted codes to elaborated codes.

The second approach found out in Bernstein's work that can inspire analyses in Popular Education concerns the so-called communicative pedagogy. In this sense, Bernstein (2000) initially asks the following: are there any general principles underlying the transformation of knowledge into pedagogic communication, whether the knowledge is intellectual, practical, expressive, or official knowledge or local knowledge?

He starts to answer this question by way of a discussion of the language device. The language device is that which mediates between the meaning potential of a discursive order and the actual meanings realized. He proposes that the pedagogic device, in a manner similar to the functioning of the language device, mediates between the field of potential pedagogic meanings and what emerges as pedagogic communication. The first point to note here is that there is no pedagogy without pedagogic communication and, second, that the pedagogic device structures pedagogic communication. So, what we have is a picture of a message flowing between a sender and a receiver with the intention of achieving a specific production that is a meaning effect (Davis, 2004).

Now when we attend to the structuring of curricula and pedagogic discourse, we note that the demand for curriculum and pedagogic change indicates that pedagogic communication has, for whatever reasons, come to be recognized as failing in some respect. We can proceed from such a realization in different directions. One direction we may take is that which is grounded in the belief, even if only implicitly in the form of an unstated assumption, that a form of communication approaching 'full' pedagogic communication is possible and that we have just not cracked the problem of isolating the conditions of possibility for such communication (Davis, 2004, p. 46).

The result of moving in this direction appears to be a preoccupation with producing increasingly fine-grained analyses of the types of knowledge that serve as resources in apparently successful pedagogic communication, followed by attempts at translating the results of such analyses into prescriptions for curriculum and course design as well as into prescriptions for pedagogic practice.

As stated by Bernstein (2000), it is worth noting that the notion of communication is necessitated by the 'problem' of the absence of a completely unified social consciousness; or, in other words, the issue of communication arises directly from the operation of power, since power distinguishes between persons and groups of persons and establishes hierarchies of access to social goods, including forms of consciousness and practice. Human communication is therefore one means by which an attempt is made to cover over a primordial (fundamental) discord at the heart of the social - a discord always-already indexed by the notion of power. So there necessarily always exists 'noise' interfering with the flow of a message between sender and receiver - between teacher and student in this instance - because a perfect communio does not and cannot exist (Davis, 2004).

Such an analysis provides the basis for a review and refinement of the approaches that have being developed on the notion of dialogue in the field of Popular Education. Frequently, these approaches picture the pedagogic relation as merely triadic (sender, receiver, product), and so they exclude from consideration the effect of the absence of linearly 
deterministic causal necessity; in other terms, they ignore the operation of a lack (of causal necessity) in the structuring of pedagogic communication. But in the flow of pedagogical communication, there is a fourth term which is prior to sender and receiver, and this primary position in the flux of communication can be called truth.

Consequently, the notion of 'full and perfect pedagogical dialogue', highlighted by many approaches in Popular Education, must be revised. The full pedagogical dialogue is a regulative ideal rather than an empirically realizable event. In other terms, it's something akin to an imperative establishing a moral horizon for pedagogic communication, as the expression of a desire for what ought-to-be in opposition to what is

The third approach found out in Bernstein's work that can inspire analyses in Popular Education is related to social change. His defence of social justice and his commitment to avoid wasting the educational potential of the working class demonstrate that he took into account the relationship between social change and education. Social change in Bernstein's thought is influenced by a neo-Marxist perspective. As Apple (1992) affirms, Bernstein describes new ways of approaching relationships between culture and power, noting the neo-Marxist-oriented sociology of education, and stressing the importance of keeping class relations in the forefront in education. Neo-Marxism can be defined as a term applied to social theory or sociological analysis which draws on the ideas of Karl Marx and Friedrich Engels, but amends or extends them by incorporating elements from other intellectual traditions such as psychoanalysis and Weberian sociology (Marshall and Scott, 2005).

According to neo-Marxism, subject is dominated by structures, but with knowledge and action, it is possible to deconstruct the power systems and the interests that lie behind them. In other words, human agency can act to create a more just society. For instance, on the hand, although structures dominate schools, students are not passive internalizers of pre-given social messages; on the other hand, contradictions are inherent to the capitalist system, and contradictory positions emerge within institutions such as school. Educational institutions have a degree of relative autonomy. Therefore, neo-Marxist perspective sees the school as both engaged in producing culture as well as reproducing cultural and economic values.

Bernstein demonstrates that education is involved in power relations, and thus he denaturalizes state educational discourses. This is fundamental to the processes of social change, since social change takes place in human interactions, and the knowledge that is deemed valid by state is a powerful influence on our subjective interpretation of ourselves and society. In other words, society is a web of social relationships and hence social change means change in the system of social relationships. It alters norms, values, cultural products and symbols in society, but it implies, above all other things, alteration in the structure and functions of a social system.

Education can initiate processes of social change bringing about an alteration in the perspective and attitudes of human beings. It can bring about a modification in the pattern of social relationships and institutions. As we have seen, Bernstein's work contributes in this direction.

\section{CONCLUSION}

Bernstein's project, from his early work on language, to the development of code theory, to the work on curriculum and pedagogic practice and discourse, was to develop a systematic theory that provides an analytic description of the way in which the educational system is related to the social division of labour (Sadovnik, 2001). However, theory, for Bernstein, has at least a two-pronged role.

The first is to grasp the real, as it is, so to speak, an already formidable task due to the inescapability of the discursive gap at the heart of pedagogic discourse. On the other hand, the real itself is to be understood not in a static sense, but in a dynamic one, since every actually existing real nurtures within it a series of alternative possible futures. This second, pre-eminent role of theory is to grasp the real as the realization of one of a series of logical possibilities. In other terms, the task is always not only to map an existing state of affairs, but to understand that state as an actualized possibility, with determinate features of variation, alongside other virtual possible worlds with equally determinate features of variation (Muller, 2004). It is these possible worlds, when delineated, which offer themselves up for political choice and action.

Such a perspective, we can finally conclude, promotes the meeting between Bernstein and Population Education, inasmuch as Popular Education has at least three main features (Schugurensky, 2000), namely, (1) recognition of the relations between knowledge and power and between structure and agency, and the acknowledgment that education can play a role to reinforce but also to challenge oppressive social relations; (2) a participatory pedagogy that focuses on the collective, departs from people's daily lived experiences and promotes an integration of popular and systematized (scientific) knowledge; (3) an attempt to constantly relate education and social action, linking critical reflection with research. 


\section{REFERENCES}

Apple, M. W. (1992): Education, culture, and class power: Basil Bernstein and the neo-Marxist Sociology of Education, in Educational Theory, vol. 4, nº 2, p. 127-145.

Atkinson, P. (1985): Language, structure and reproduction: an introduction to the sociology of Basil Bernstein. London, Methuen.

Bernstein, B (2000): Pedagogy, symbolic control and identity. New York: Rowman and Littlefield.

Bernstein, B. (1990): Class, codes and control, vol. 4: the structuring of pedagogic discourse. London, Routledge.

Bernstein, B. (1977): Class, codes and control, vol. 3. London: Routledge \& Kegan Paul.

Bernstein, B (1973): Class, codes and control, vol. 2. London, Routledge \& Kegan Paul.

Bernstein, B. (1962a): Linguistic codes, hesitation phenomena and intelligence, in Language and speech (Teddington, $U K)$, vol. 5, no. 1, p. 31-46.

Bernstein, B. (1962b): Social class, linguistic codes and grammatical elements, in Language and speech (Teddington, UK), vol. 5, no. 4, p. 221-40.

Bernstein, B. (1961a): Social class and linguistic development: a theory of social learning, in Halsey, A.H., Floud, J. \& Anderson, C.A.(eds), Education, economy and society. New York: Free Press, p. 288-314

Bernstein, B. (1961b): Social structure, language and learning, in Educational Research, London, vol. 3, nº. 3, p. 163-76.

Bernstein, B. (1960): Language and social class: a research note, in British Journal of Sociology, London, vol. 11, no. 3 , p. 271-76.

Bowles, S.; Gintis, H. (1976): Schooling in capitalist America. New York, Basic Books.

Braster, S. (2011): The people, the poor, and the oppressed: the concept of popular education through time, in Paedagogica Historica, 47(1-2), 1-14.

Carrillo, A. T. (2011): La educación popular: Trayectoria y actualidad. Caracas: Universidad Bolivariana de Venezuela.

Danzig, A. (1995): Applications and distortions of Basil Bernstein's code theory, in Sadovnik, A.R. (ed), Knowledge and pedagogy: the sociology of Basil Bernstein, p. 145-70. Norwood, NJ: Ablex Publishing.

Davis, Z. (2004): The debt to pleasure: the subject and knowledge in pedagogic discourse, in Johan Muller, Brian Davies and Ana Morais, Reading Bernstein, Researching Bernstein. London: RoutlendgeFalmer.

Freire, Paulo (1991): A Educação na Cidade. São Paulo: Cortez.

Freire, Paulo (1970): Pedagogia do oprimido. Rio de Janeiro: Paz e Terra.

Kane, L.(2013): Comparing 'popular' and 'state' education in Latin America and Europe, in European Journal for Research on the Education and Learning of Adults, 4(1), p. 81-96.

Kane, L. (2001): Popular Education and social change in Latin America. London: Latin American Bureau.

Marshall, G. and Scott, J. (2005): A Dictionary of Sociology. New York: Oxford University Press.

McLean, M.; Abbas, A.; Ashwin, P. (2012): The use and value of Bernstein's work in studying (in)equalities in undergraduate social science education, in British Journal of Sociology of Education, 34(2), p. 1-19.

Morrow, R. A.; Torres, C. A. (2002): Reading Freire and Habermas: Critical Pedagogy and transformative social change. New York: Teachers College Press.

Muller, J. (2004): The possibilities of Basil Bernstein, in Johan Muller, Brian Davies and Ana Morais, Reading Bernstein, Researching Bernstein. London: RoutlendgeFalmer.

Nicholas, V. (2001): When the personal became the educational: towards an ecofeminist popular education in, CONCEPT, 11(3), 29-30.

Sadovnik, A. R. (2001): Basil Bernstein (1924-2000), in Prospects: the quarterly review of comparative education, Paris (UNESCO: International Bureau of Education), vol. XXXI, n 4 , December 2001, p. 687-703. 
Scandrett, E. (2001): Popular education and ideology? A response, in CONCEPT, 11(2), 15-16.

Schugurensky, D. (2000): Adult education and social transformation: On Gramsci, Freire and the challenge of comparing comparisons, in Comparative Education Review, 44(4), p. 515-522.

Steele, T. (2007): Knowledge is power!: the rise and fall of European Popular educational movements, 1848-1939. Bern: Peter Lang.

Tiana Ferrer, A. (2011): The concept of popular education revisited - or what do we talk about when we speak of popular education, in Paedagogica Historica, 47(1-2), 15-31.

Zarco, C. (2001). Review of Chapter 1, in Liam Kane (ed), Popular Education and Social Change in Latin America (pp. 29-32). London: Latin American Bureau. 